\title{
Адсорбция L-пролина на углеродных нанотрубках при различных температурах
}

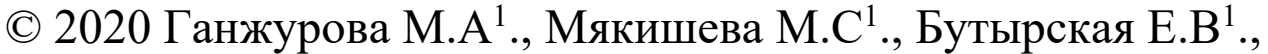 \\ Боровикова С.А. ${ }^{2}$, Коломиец Л.Н. ${ }^{2}$ \\ ${ }^{l}$ ФГБОУ ВО «Воронежский государственный университет», Воронеж \\ ${ }^{2}$ ФГБУН «Институт физической химии и электрохимии им. А.Н. Фрумкина РАН», Москва
}

Поступила в редакцию 14.03 .2020 г.

DOI: $10.17308 /$ sorpchrom.2020.20/2777

Углеродные нанотрубки (УНТ) - полые цилиндрические структуры, которые состоят из атомов углерода. Актуальность исследования физико-химических свойств обусловлено их уникальными сорбционными и электронными свойствами, механической прочностью. Аминокислоты (АК) - одни из главных представителей биологически активных веществ, которые участвуют во многих процессах жизнедеятельности человека. Поэтому для биомедицинских приложений является приоритетом исследование взаимодействия аминокислот с нанотрубками.

Цель работы - построение изотерм адсорбции L-пролина на углеродных нанотрубках при различных температурах и их дальнейшая интерпретация. Предметом исследования в нашей статье является изучение влияния температуры на адсорбцию L-пролина на углеродных нанотрубках. Объекты исследования - водные растворы L-пролина, углеродные нанотрубки МКнано-S1 (Канада). Методы исследования - диспергирование, фотометрия, объемный метод построения изотерм адсорбции в сочетании с методом переменных концентраций, методы квантовой химии.

Построены изотермы адсорбции аминокислоты L-пролина на углеродных нанотрубках МКнано-S1 (Канада) из водных растворов при температурах $\mathrm{T}=25,45,65^{\circ} \mathrm{C}$. Изотермы имеют S-образный вид. Адсорбция L-пролина на углеродных нанотрубках растет с увеличением температуры. Это объясняется увеличением площади поверхности сорбента с ростом температуры из-за разбиения агломератов УНТ. На основе кластерной модели адсорбции установили, что L-пролин сорбируется в форме мономеров при $\mathrm{T}=25^{\circ} \mathrm{C}$ и кластеров размерностей $19\left(\mathrm{~T}=65^{\circ} \mathrm{C}\right)$ и $23\left(\mathrm{~T}=45^{\circ} \mathrm{C}\right)$ Методами квантовой химии была выполнена оптимизация структуры систем мономер L-пролин - УНT. Для энергий адсорбции получено: $\mathrm{E}_{\text {кон }}>\mathrm{E}_{\text {внутри }}>\mathrm{E}_{\text {бок. }}$.

Ключевые слова: углеродные нанотрубки (наночастицы), аминокислоты, адсорбция, компьютерное моделирование, квантово-механический расчет.

\section{Введение}

Углеродные нанотрубки (УНТ) - новый тип наносорбентов с уникальными структурными, механическими, оптическими, электрическими и сорбционными свойствами [1-7]. Вследствие уникальности свойств нанотрубок, они являются решающим материалом для задач биомедицины, таких как разработка платформ адресной доставки лекарств, биосенсоров нового поколения, тканевой инженерии и другие [8-11]. Реализация свойств нанотрубок в биотехнологиях требует понимания природы взаимодействия биомолекул и УНТ [12-18]. Простейшей единицей большого числа биомолекул являются аминокислоты (АК). Таким образом, взаимодействие между УНТ и АК являются важными для понимания механизма взаимодействия нанотрубок с биомолекулами.

Целью данной работы являлось изучение влияния температуры на адсорбцию L-пролина углеродными нанотрубками из водных растворов. 


\section{Эксперимент}

Объектами исследования являлись одностенные углеродные нанотрубки марки MKN-SWCNT-S1(Канада) и аминокислота L-пролин (Sigma-Aldrich). Определение аминокислоты в водном растворе проведено методом градуировочного графика с использованием методики получения медного комплекса аналита. Для построения градуировочного графика готовили водные растворы аминокислоты с концентрациями 0.01-0.05 моль/дм³ . В аликвоты (по $5 \mathrm{~cm}^{3}$ раствора каждой концентрации) добавляли по $5 \mathrm{~cm}^{3}$ раствора $0.1 \mathrm{M}$ водного раствора сульфата меди (II), после чего в полученные смеси по каплям добавляли $0.1 \mathrm{M}$ водный раствор $\mathrm{NaOH}$ до помутнения. Затем содержимое колб доводили до метки $\mathrm{V}=25 \mathrm{~cm}^{3}$ водой, тщательно перемешивали и отфильтровывали полученные суспензии через складчатый фильтр. Оптическую плотность фильтрата измеряли с помощью колориметра КФК-2 (кюветы с толщиной поглощающего слоя $3 \mathrm{~cm}$, аналитическая длина волны $\lambda=670 \mathrm{Hм})$.

Для выявления времени установления равновесия в водных растворах УНТ - Lпролин готовили водный раствор L-пролина с концентрацией 0.04 моль/дм³. В 8 колб помещали одинаковые навески УНТ (0.01 г), после чего каждую колбу заливали $5 \mathrm{~cm}^{3}$ данного раствора, обрабатывали все растворы ультразвуком и помещали в шейкеринкубатор при требуемой температуре. Через каждый час одну из колб с суспензий вынимали и анализировали.

Для определения адсорбционной способности аминокислоты на углеродных нанотрубках навеску 0.01 г углеродных наночастиц заливали водным раствором аминокислоты различных концентраций. Затем полученные растворы обрабатывали ультразвуком в течение 3 мин с использованием установки МЭФ91. Полученные суспензии перемешивали до установления равновесия при температурах $25,45,65^{\circ} \mathrm{C}$ в шейкер-инкубаторе ES-20. Приготовленные растворы отфильтровывали через складчатый фильтр (марки «красная лента») и центрифугировали. Затем проводили определение концентрации L-пролина в супернатанте фотометрически. Построение изотерм адсорбции проводили объемным методом в сочетании с методом переменных концентраций.

В условиях эксперимента значение $\mathrm{pH}$ раствора находилось в интервале от 5.43 до 5.60. При данных значениях $\mathrm{pH}$ пролин в водном растворе существует в форме цвиттер-иона.

Квантово-химическое моделирование систем систем «L-пролин-УНT» проводили с помощью программы Gaussian09 методом B32LYP/6-31G(d,p) GD3, который позволяет выполнить расчет энергий исследуемых структур с учетом дисперсионных поправок [19].

Учет растворителя проводили методом поляризационного континуума Томаси [20]. Энергию взаимодействия аминокислоты и УНТ рассчитывали по формуле:

$$
\mathrm{E}_{\mathrm{ad}}=\text { Еунт }+\mathrm{E}_{\text {сорбат }}-\mathrm{E}_{\text {сорбат }+ \text { УНТ }}
$$

где Е аминокислоты; Есорбат+унт - энергия системы «аминокислота - УНТ».

В качестве модельной нанотрубки использована нанотрубка хиральности (6.6) длиной 0.5-2 нм. Использованные в эксперименте нанотрубки имеют закрытые концы. При квантово-химическом моделировании элементарного акта адсорбции на УНТ использована нанотрубка с открытыми концами и выполнено моделирование на внешней боковой поверхности трубки, что обусловлено следующим. Использованные нанотрубки имеют низкую концентрацию дефектов, поэтому проникновение сорбата внутрь УНТ маловероятно. Отношение длины нанотрубки к ее диаметру равно $\sim 833$. 
Следовательно, на боковой поверхности УНТ будет сорбироваться значительно большее количество сорбата, чем на ее конечных участках. Поэтому вклад в изотерму, обусловленный адсорбцией концами УНТ, будет значительно меньше, чем вклад адсорбции боковой поверхностью. Использование в расчетах трубки с открытыми концами обусловлено сложностью процедуры закрытия концов нанотрубки при компьютерном моделировании и слабым влиянием конечных участков трубки на адсорбцию боковой поверхностью.

Изотермы также проинтерпретированы на основе модели адсорбции, разработанной в работе [21] для случая существования молекул сорбтива А во внешнем растворе в форме мономеров, из которых на поверхности сорбента S формируются кластеры различных размерностей в соответствии с уравнениями:

$$
\left\{\begin{array}{c}
S+A=S A \\
\cdots \\
S+n A=S A_{n}
\end{array}\right.
$$

Уравнение адсорбции при этом имеет вид [21]:

$$
q=q_{m} \frac{K_{1} C_{e}+\frac{2}{m_{2}} K_{2} C_{e}^{2}+\cdots \frac{i}{m_{i}} K_{i} C_{e}^{i}+\cdots+\frac{n}{m_{n}} K_{n} C_{e}^{n}}{1+K_{1} C_{e}+K_{2} C_{e}^{2}+\cdots \frac{i}{m_{i}} K_{i} C_{e}^{i}+\cdots+K_{n} C_{e}^{n}},
$$

где $q$ - величина адсорбции, $\mathrm{C}_{\mathrm{e}}-$ равновесная концентрация, моль/дм ${ }^{3} ; q_{m}-$ емкость монослоя, моль/г; $K_{i}$ - коэффициенты равновесия процессов (1), $i(n)$ - текущая (максимальная) размерность сорбированных кластеров; $m_{i}-$ число мономеров сорбата первого (нижнего) слоя кластера размерности i.

\section{Обсуждение результатов}

На рис.1. представлены интегральные кинетические кривые сорбции L-пролина из водных растворов на углеродных нанотрубках MKN-SWCNT-S1 (Канада) при разных температурах.

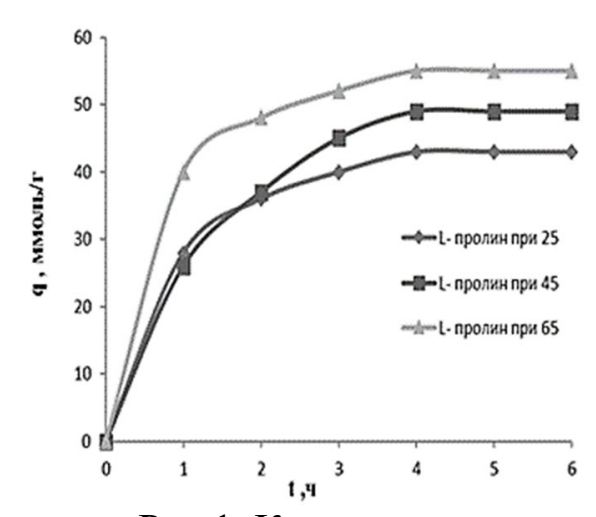

Рис.1. Кинетические кривые $\mathrm{L}$-пролина при при $25,45,65^{\circ} \mathrm{C}$.

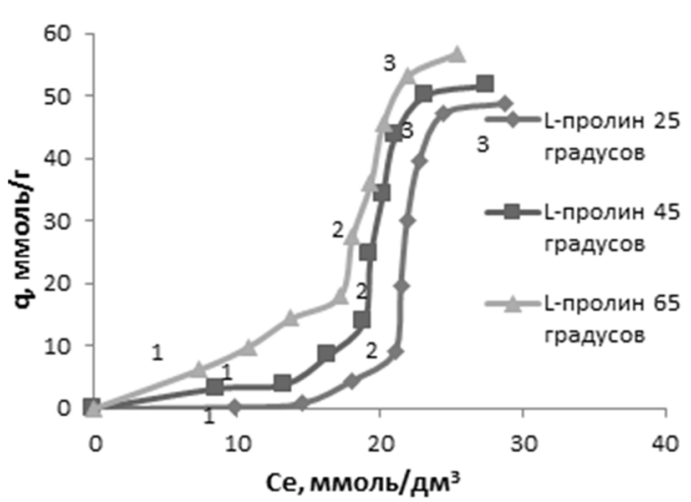

Рис.2. Изотермы сорбции L-пролина на УНT MKN-SWCNT-S1 при температурах $25,45,65^{\circ} \mathrm{C}$.

Эксперимент показал, что время установления равновесия в исследуемых системах для всех температур составляет 6 часов. На рис. 2 представлены изотермы адсорбции L-пролина на УНT марки MKN-SWCNT-S1(Канада).

Изотермы адсорбции L-пролина для температур 25,45 и $65{ }^{\circ} \mathrm{C}$ имеют $\mathrm{S}$ - образный вид и принадлежат к IV $\left(45\right.$ и $\left.65^{\circ} \mathrm{C}\right)$ и $\mathrm{V}\left(25^{\circ} \mathrm{C}\right)$ типам по классификации ИЮПАК. На изотермах можно выделить 3 участка с различной величиной и скоростью адсорбции. Для температуры $25^{\circ} \mathrm{C}$ адсорбция при низких концентрациях практически отсутствует (участок 1). При увеличении концентрации от 14 до 21 моль/дм ${ }^{3}$ 
имеет место незначительное увеличение скорости адсорбции с увеличением концентрации сорбтива (участок 2), о чем свидетельствует увеличение наклона изотермы по сравнению с участком 1. При С $>21$ моль/дм ${ }^{3}$ адсорбция резко возрастает (участок 3 ).

Для температуры $45^{\circ} \mathrm{C}$ величина адсорбции на участке 1 больше, чем при $25^{\circ} \mathrm{C}$ и становится отличной от 0 при малых концентрациях. На участке 2 скорость адсорбции больше, чем на первом участке, поскольку наклон изотермы увеличивается. Участок 3 с резким ростом адсорбции начинается при С 19 моль/дм³.

Для температуры $65^{\circ} \mathrm{C}$ величина адсорбции на участке 1 более существенна, чем при $45^{\circ} \mathrm{C}$. Участок 2 возможно означает выход на плато начальной части изотермы (участка 1). Участок 3 с резким ростом адсорбции начинается при $\mathrm{C}=17$ моль/дм ${ }^{3}$. C ростом температуры адсорбция увеличивается, а концентрация, с которой начинается резкий рост адсорбции, уменьшается. Такая температурная зависимость величины адсорбции может быть объяснена увеличением площади поверхности сорбента с ростом температуры вследствие более существенного разбиения агломератов УНТ. Поскольку при $\mathrm{T}=25^{\circ} \mathrm{C}$, адсорбция при малых концентрациях сорбтива не наблюдается, была проведена оценка энергии адсорбции L-пролина на углеродных нанотрубках методами квантовой химии для оценки энергетической выгодности адсорбции.

В результате компьютерного моделирования элементарного акта адсорбции L-пролина на боковой поверхности нанотрубок было найдено несколько вариантов расположения аминокислоты на внешней боковой поверхности. Оптимизированные структуры систем «аминокислота - нанотрубка» и наименьшие расстояния от атомов кислорода и азота аминокислоты до атомов углерода нанотрубки представлены в табл.1.

Таблица 1. Структура, энергия адсорбции (Eads, ккал/моль), наименьшее расстояние от атомов кислорода и азота аминокислоты до атомов углерода нанотрубки ( $\mathrm{R}_{\mathrm{CO} 1,} \mathrm{R}_{\mathrm{CO} 2,} \mathrm{R}_{\mathrm{CN}}$ ).

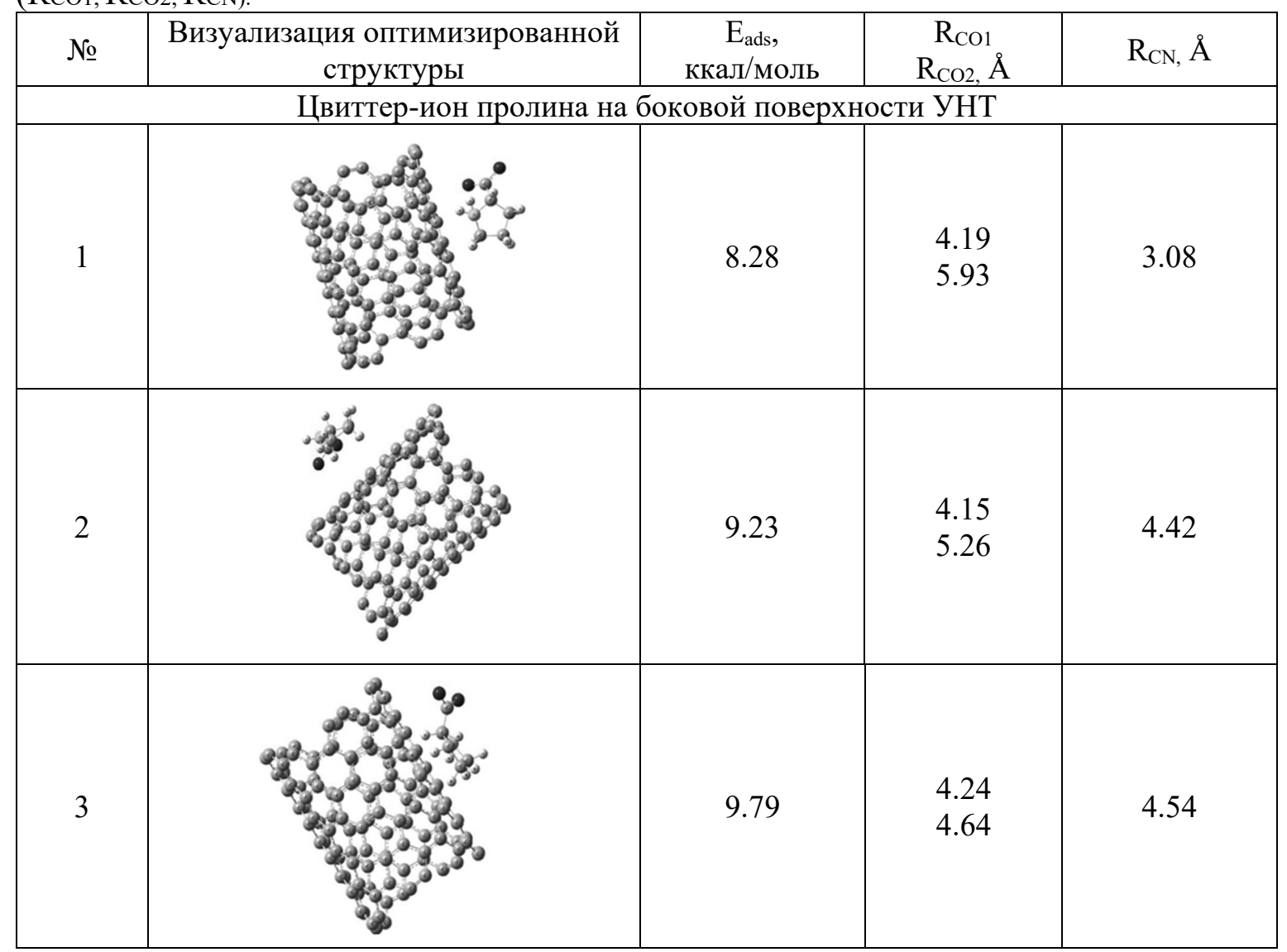


Наибольшая энергия адсорбции имеет место при расположении пирролидинового кольца аминокислоты практически параллельно поверхности нанотрубки (структура 3, табл.1). Значения расстояний от атомов аминокислоты до нанотрубки позволяют сделать вывод, что аминокислота закрепляется на поверхности УНТ посредством взаимодействий Ван-дер-Ваальса. Расчет показывает, что адсорбция аминокислоты на УНТ энергетически выгодна. Тем не менее, при $\mathrm{T}=25^{\circ} \mathrm{C}$, адсорбция при малых концентрациях сорбтива не наблюдается.

Возможное объяснение этому состоит в следующем. В работе [23] исследованы водные растворы различных концентраций L-пролина методами дифракции нейтронов с изотопным замещением, уточнения структуры эмпирического потенциала и малоуглового рассеяния нейтронов. Показано, что полярные части пролина достаточно сильно гидратированы, однако тетраэдрическая структура воды при этом не нарушена и отсутствует ассоциация с другими молекулами пролина. Вследствие этого взаимодействие аминокислоты с растворителем является достаточно сильным. Цвиттерионы пролина прочно удерживаются водным раствором при малых концентрациях и комнатной температуре, что препятствует диффузии сорбтива к сорбенту. При увеличении концентрации пролина взаимодействие цвиттер-ионов аминокислоты с растворителем уменьшается, что приводит к резкому росту величины адсорбции.

Уравнения изотерм исследованных процессов получены методом нелинейной подгонки экспериментальных изотерм (рис.2) к виду (3):

$$
\begin{aligned}
q & =q_{m_{1}} \frac{\kappa_{23}^{(1)} \mathrm{c}_{\mathrm{e}}^{23}}{1+K_{23} \mathrm{c}_{\mathrm{e}}^{23}} \text { для } \mathrm{T}=25^{\circ} \mathrm{C}\left(298^{\circ} \mathrm{K}\right) \mathrm{R}^{2}=0.9972 \\
q & =q_{m_{2}} \frac{\mathrm{K}_{1}^{(2)} \mathrm{c}_{\mathrm{e}}+\mathrm{K}_{23}^{(2)} \mathrm{c}_{\mathrm{e}}^{23}}{1+\mathrm{K}_{1}^{(2)} \mathrm{e}_{\mathrm{e}}+\mathrm{K}_{23}^{(2)} \mathrm{c}_{\mathrm{e}}^{23}} \text { для } \mathrm{T}=45^{\circ} \mathrm{C}\left(318^{\circ} \mathrm{K}\right) \mathrm{R}^{2}=0.9935 \\
q & =q_{m_{3}} \frac{\mathrm{K}_{1}^{(3)} \mathrm{c}_{\mathrm{e}}+\mathrm{K}_{19}^{(3)} \mathrm{c}_{\mathrm{e}}^{19}}{1+\mathrm{K}_{1}^{(3)} \mathrm{c}_{\mathrm{e}}+\mathrm{K}_{19}^{(3)} \mathrm{c}_{\mathrm{e}}^{19}} \text { для } \mathrm{T}=65^{\circ} \mathrm{C}\left(338^{\circ} \mathrm{K}\right) \mathrm{R}^{2}=0.9959
\end{aligned}
$$

Параметры, входящие в (4)-(6), для $\mathrm{c}_{\mathrm{e}}=\mathrm{C}_{\mathrm{e}} / 10$, представлены в таблице 2.

Таблица 2. Значения параметров уравнения изотермы адсорбции L-пролина на УНT MKNSWCNT-S1 (Канада), полученные методом нелинейной подгонки уравнения (2) к экспериментальным изотермам.

\begin{tabular}{|c|c|c|c|c|}
\hline $\mathrm{T}\left({ }^{\circ} \mathrm{C}\right)$ & $\mathrm{q}_{\mathrm{m}, \text { ммоль } / \Gamma}$ & $\mathrm{K}_{1, \text { ммоль } / \text { дм }^{3}}$ & $\mathrm{~K}_{23^{(1)}}, \mathrm{K}_{23}{ }^{(\mathcal{L})}, \mathrm{K}_{19}{ }^{\left({ }^{(ग)}\right.}$ & $\mathrm{R}^{L}, \mathrm{~A}$ \\
\hline 25 & 4.393 & - & $1.553 \cdot 10^{(-8)}$ & 0.9972 \\
\hline 45 & 45.137 & 0.07622 & $1.587 \cdot 10^{(-7)}$ & 0.9935 \\
\hline 65 & 49.155 & 0.211 & $5.514 \cdot 10^{(-6)}$ & 0.9959 \\
\hline
\end{tabular}

* размерность $\mathrm{K}_{23}{ }^{(1,2)}$ - $\left(\text { ммоль/дм }{ }^{3}\right)^{23} ; \mathrm{K}_{19}{ }^{(3)}$ - $\left(\text { ммоль } / \text { дм }^{3}\right)^{19}$.

В соответствии со смыслом параметров уравнения (2) можно сделать вывод, что L-пролин сорбируется на УНТ в виде кластеров размерности 23 при $\mathrm{T}=25^{\circ} \mathrm{C}$, мономеров и кластеров размерностей $23\left(\mathrm{~T}=45^{\circ} \mathrm{C}\right)$ и $19\left(\mathrm{~T}=65^{\circ} \mathrm{C}\right)$.

Уравнения изотерм (4) и (5) могут быть представлены в виде

$$
q=q_{1}+q_{23} \text { и } q=q_{1}+q_{19}
$$

Слагаемые $q 1, q 19, q_{23}$ представляют собой вклады в адсорбцию мономеров и кластеров размерностей 19 и 23. На рис. 3-5 представлены экспериментальные и теоретические изотермы адсорбции и парциальные вклады в адсорбцию мономеров и кластеров L-пролина для различных температур.

Быстрый рост значений адсорбции описывается вкладами в адсорбцию членов q19 и q23 (6) (рис. 4-5). Таким образом, резкий рост величины адсорбции обусловлен формированием на поверхности нанотрубки кластеров L-пролина размерности 23 при $\mathrm{T}=25^{\circ} \mathrm{C}, \mathrm{T}=45^{\circ} \mathrm{C}$ и 19 при $\mathrm{T}=65^{\circ} \mathrm{C}$. 


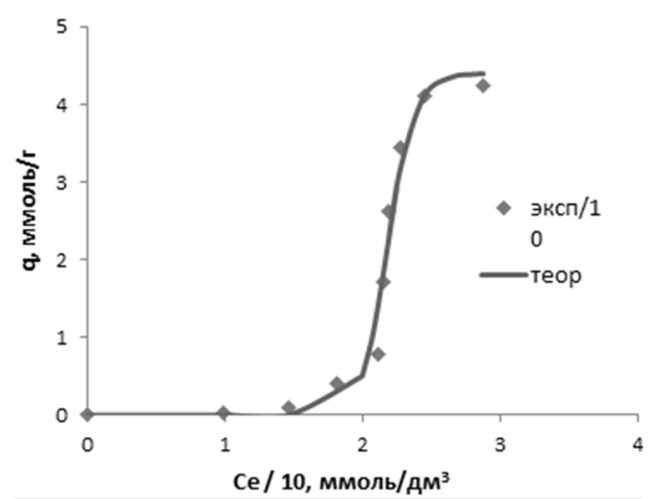

Рис. 3. Экспериментальная (точки) и теоретическая (уравнение (4)) изотермы

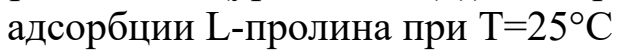

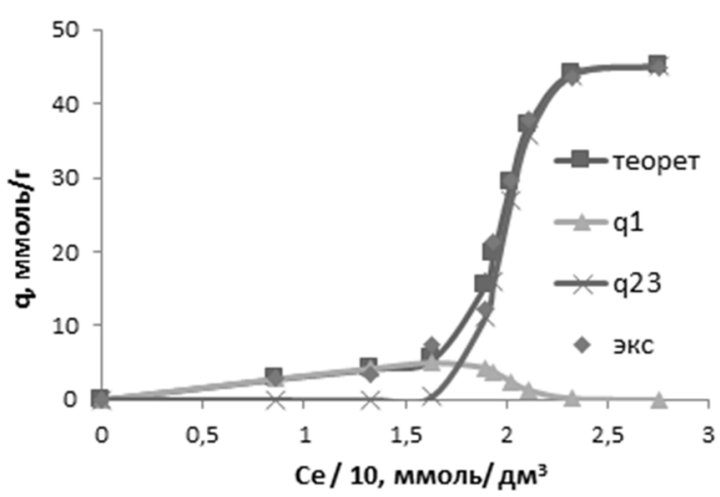

Рис.4. Экспериментальная (точки) и теоретическая изотермы адсорбции $\mathrm{L}$-пролина при $\mathrm{T}=45^{\circ} \mathrm{C}$ на углеродных нанотрубках MKN-SWCNT-S1.

Разложение теоретической кривой на вклады в адсорбцию мономеров (q1) и кластеров размерности 23 (q23).

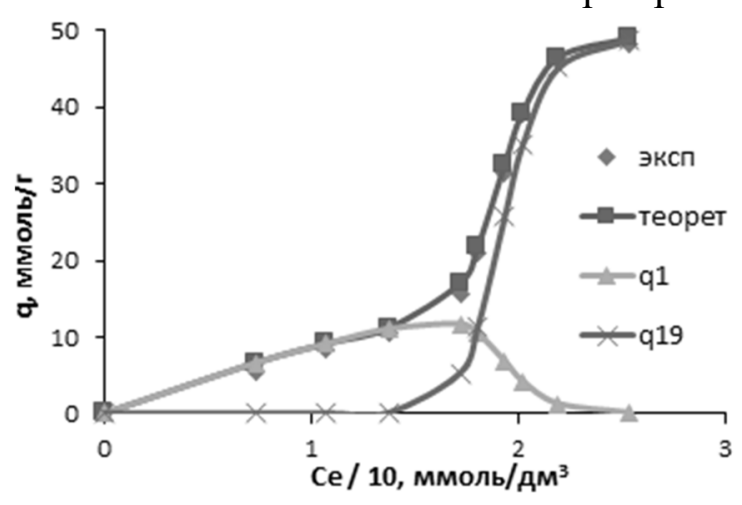

Рис. 5. Экспериментальная (точки) и теоретическая изотермы адсорбции L-пролина при T $=65^{\circ} \mathrm{C}$ на углеродных нанотрубках MKN-SWCNT-S1. Разложение теоретической кривой на вклады в адсорбцию мономеров (q1) и кластеров размерности 19 (q19).

\section{Заключение}

Анализ изотерм адсорбции L-пролина на углеродных нанотрубках MKNSWCNT-S1 из водного раствора, построенных для различных температур $\left(\mathrm{T}=25^{\circ} \mathrm{C}\right.$, $\mathrm{T}=45^{\circ} \mathrm{C}, \mathrm{T}=65^{\circ} \mathrm{C}$ ) демонстрирует рост величины адсорбции с увеличением температуры. Это указывает на увеличение площади поверхности сорбента с ростом температуры вследствие более существенного разбиения агломератов УНТ. Форма изотерм адсорбции свидетельствует о медленном росте величины адсорбции при низких концентрациях внешнего раствора и ее скачкообразном росте, начиная с некоторого значения концентрации, зависящего от температуры. Медленный рост адсорбции проинтерпретирован удерживанием цвиттер-ионов пролина в водном растворе вследствие сильного взаимодействия с растворителем, что следует из анализа литературы. Увеличение концентрации пролина приводит к снижению взаимодействия цвиттер-ионов аминокислоты с растворителем вследствие разрушения структуры последнего. Это приводит к адсорбции аминокислоты на поверхности сорбента в форме кластеров и 
резкому росту величины адсорбции. На основе модели адсорбции, описывающей процесс формирования на поверхности сорбента кластеров различных размерностей из мономерных молекул сорбтива внешнего раствора показано, что на поверхности нанотрубки формируются кластеры L-пролина размерности 23 при $\mathrm{T}=25^{\circ} \mathrm{C}$, мономеры и кластеры размерности 23 при $\mathrm{T}=45^{\circ} \mathrm{C}$, мономеры и кластеры размерности 19 при $\mathrm{T}=65^{\circ} \mathrm{C}$.

\title{
Список литературы
}

1. Елецкий А.В. // УФН. 1997. Т.167. № 9. C. 945-972.

2. Раков Э.Г. // Успехи химии. 2013. № 82 (1). C. 27-47.

3. Раков Э.Г. // Успехи химии. 2001. Т. 70.№ 10. C.934-973.

4. Dai H., Hafner J.H., Rinzler A.G., Colbert D.T. et al. // Nature. 1996. Vol. 384. pp.147-150.

5. Zhai P., Isaacs J.A., Eckelman M.J. // Appl.Energy. 2016. Vol. 173. pp. 624-634.

6. Upadhyayula V.K.K., Deng S., Mitchell M.C., Smith G.B. A. // Sci. Total Environ. 2009. Vol. 408. pp. 1-13.

7. Bianco A., Kostarelos K., Partidos C.D., Prato M. // Chem. Commun. Camb. Engl. 2005. pp. 571-577.

8. Hadi Zare Zardini, Ahmad Amiri, Mehdi Shanbedi, Morteza Maghrebi et al. // Colloids and Surfaces. Biointerfaces. 2012. Vol. 92. pp. 196-202.

9. Kumar, Ruma Rani, Neeraj Dilbaghi, Tankeshwarab K. // The Royal Society of Chemistry. 2016. Vol. 4. pp. 215-338.

10. Vardharajula S., Ali S. Z., Tiwari P. M., Eroglu E. et al. // Int. J. Nanomedicine. 2012.Vol.13. pp. 5361-5374.

11.de Leon A., Jalbout A.F., Basiuk V.A. // Chemical Physics Letters. 2008. Vol. 457. pp. 185-190.
12.Butyrskaya E.V., Zapryagaev, S.A., Izmailova E.A., Nechaeva L.S. // J. Phys. Chem. C. 2017. Vol. 121. No 37. pp. 20524-20531.

13.Zhongjin He, Jian Zhou // Carbon. 2014. Vol. 78. pp. 500-509.

14.Lingyu Piao, Quanrun Liu, Yongdan Li. // J. Phys. Chem. C. 2012. Vol. 116. pp. 1724- 1731.

15.Нечаева Л.С., Бутырская Е.В., Запрягаев С.А. // Журнал структурной химии. 2017. № 2. C. 233-241.

16.Garalleh H.A.L., Thamwattana N., Cox B.J., James M.H. // J. of Biomaterials and Tissue Engineering. 2016. No 6. pp. 362-369.

17.Roman T., Dino W.A., Nakanishi H., Kasai H. // Eur. Phys. J. D. 2006. Vol. 38. pp. 117-120.

18. Grimme S., Antony J., Ehrlich S., Krieg H. // J. Chem. Phys. 2010. Vol. 132. pp. 154104154119.

19.Miertus S. // Chem. Phys. 1981. Vol. 55. No 1.pp. 117-129.

20.Dalton A.B. // Nature. 2003. Vol. 423. pp. 703-712.

21.Butyrskaya E.V., Zapryagaev S.A., Izmailova E.A. // Carbon. 2018. Vol.143. pp. 276287.

22. Sylvia E. McLain, Alan K. Soper, Ann E. Terry Anthony Watts. // Chem. Phys. 2007. No 111. pp. $4568-4580$

\section{Adsorption of L-proline on carbon nanotubes at different temperatures}

\author{
(C) 2020 Ganzhurova M.A. ${ }^{1}$, Myakisheva M.S. ${ }^{1}$, Butyrskaya E.V. ${ }^{1}$, \\ Borovikova S.A. ${ }^{2}$, Kolomiets L.N. ${ }^{2}$ \\ Voronezh State University, Voronezh \\ Frumkin Institute of Physical Chemistry, Moscow
}

\begin{abstract}
Carbon nanotubes are relatively new hollow cylindrical structures consisting of carbon atoms. The study of their physicochemical properties is important due to their unique sorption and electronic properties and mechanical strength. Amino acids (AA) are one of the main representatives of biologically active substances involved in many human processes. Therefore, the study of interactions between amino acids and nanotubes is of a priority for biomedical applications.
\end{abstract}


The purpose of the work was to build isotherms of L-proline adsorption on carbon nanotubes at different temperatures and to interpret them. The subject of the research was a study of the influence of temperature on L-proline adsorption on carbon nanotubes. The object of our research was L-proline aqueous solutions and carbon nanotubes MK Nano S1 (Canada). Among the research methods were dispersion, photometry, and volumetric method of building adsorption isotherms combined with the method of variable concentrations, and methods of quantum chemistry. The following results were obtained: isotherms of L-proline amino acid ad $\mathrm{T}=25,45,65^{\circ} \mathrm{C}$. It was established that with an increase in temperature there is an increase in L-proline adsorption. The cluster adsorption model was used to establish that L-proline is adsorbed in the form of monomers and clusters with dimensions of 19 and 23 .

Isotherms of L-proline amino acid adsorption on carbon nanotubes MK Nano S1 (Canada) were built from aqueous solution at temperatures of $\mathrm{T}=25,45,65^{\circ} \mathrm{C}$.Isotherms are $\mathrm{S}$-shaped. Adsorption of L-proline on carbon nanotubes increases with an increase in temperature. This can be explained by an increase in the area of the sorbent with an increase of temperature due to carbon nanotubes agglomerate separation. Cluster adsorption model was used to establish that L-proline is adsorbed in the form of monomers at $\mathrm{T}=25^{\circ} \mathrm{C}$ and clusters with the dimension of $19\left(\mathrm{~T}=65^{\circ} \mathrm{C}\right)$ and $23\left(\mathrm{~T}=45^{\circ} \mathrm{C}\right)$.

Keywords: carbon nanotubes (nanoparticles), amino acids, adsorption, computer modelling, quantum mechanical calculations

\section{References}

1. Eleckij A.V., UFN, 1997, Vol. 167, No 9 , pp. 945-972.

2. Rakov E.G., Uspekhi khimii, 2013, No 82 (1), pp. 27-47.

3. Rakov E.G., Uspekhi khimii, 2001, Vol. 70, No 10, pp.934-973.

4. Dai H., Hafner J.H., Rinzler A.G., Colbert D.T. et al., Nature, 1996, Vol. 384. pp. 147-150. DOI: $10.1038 / 384147 \mathrm{a} 0$.

5. Zhai P., Isaacs J.A., Eckelman M.J., Appl.Energy, 2016, Vol. 173, pp. 624-634. DOI:10.1016/j.apenergy.2016.04.001.

6. Upadhyayula V.K.K., Deng PP., Mitchell M.C., Smith G.B.A., Sci. Total Environ, 2009, Vol. 408, pp. 1-13. DOI: 10.1016/j.scitotenv.2009.09.027.

7. Bianco A., Kostarelos K., Partidos C.D., Prato M., Chem. Commun. Camb. Engl., 2005, pp. 571-577. DOI: 10.1039/b410943k.

8. Hadi Zare Zardini, Ahmad Amiri, Mehdi Shanbedi, Morteza Maghrebi et al., Colloids and Surfaces. Biointerfaces, 2012, Vol. 92, pp. 196-202. DOI: 10.1016/j.colsurfb.2011.11.045.

9. Kumar, Ruma Rani, Neeraj Dilbaghi, Tankeshwarab K., The Royal Society of Chemis-try, 2016, Vol. 4, pp. 215-338. DOI: $10.1039 / \mathrm{c} 6 \mathrm{cs} 00517 \mathrm{a}$.

10.Vardharajula PP., Ali PP. Z., Tiwari P. M., Eroglu E. et al., Int. J. Nanomedicine, 2012, Vol. 13. pp. 5361-5374.

11.de Leon A., Jalbout A.F., Basiuk V.A., Chemical Physics Letters, 2008, Vol. 457, pp. 185-190. DOI: 10.1016/j.cpletVol.
2008.03.079.

12.E.V., Zapryagaev S.A., Iz- mailova E.A., Nechaeva L.S., J. Phys. Chem. C, 2017, Vol. 121, No 37, pp. 20524-20531.

DOI: $10.1021 /$ ac pp.jpcc.7b06849.

13.Zhongjin He, Jian Zhou, Carbon, 2014, Vol. 78, pp. 500-509. DOI: 10.1016/j.carbon.2014. 07.031 .

14.Lingyu Piao, Quanrun Liu, Yongdan Li., $J$. Phys. Chem. C, 2012, Vol. 116, pp. 1724-1731. DOI: $10.1021 / j p 2085318$.

15.Nechaeva L.S., Butyrskaya E.V., Zapryagaev S.A., Zhurnal strukturnoj khimii, 2017, No 2, pp. 233-241.

16. Garalleh H.A.L., Thamwattana N., Cox B.J., James M.H., J. of Biomaterials and Tissue Engineering, 2016, No 6, pp. 362-369.

17.Roman T., Dino W.A., Nakanishi H., Kasai H., Eur. Phys. J. D., 2006, Vol. 38, pp. 117-120. DOI: 10.1140/epjd/e2006-00043-1.

18. Grimme T., Antony J., Ehrlich T., Krieg H., J. Chem. Phys., 2010, Vol. 132, pp. 154104154119.

19.Miertus S., Chem. Phys., 1981, Vol. 55, No 1, pp. 117-129.

20.Dalton A.B. // Nature. 2003. Vol. 423. pp. 703-712.

21.Butyrskaya E.V., Zapryagaev S.A., Izmailova E.A. // Carbon. 2018. Vol.143. pp. 276287.

22.Sylvia E. McLain, Alan K. Soper, Ann E. Terry Anthony Watts. // Chem. Phys. 2007. No 111. pp.4568-4580. 
Ганжурова Мария Александровна - магистр химического факультета, Воронежский государственный университет, Воронеж

Мякишева Марина Сергеевна - магистр химического факультета, Воронежский государственный университет, Воронеж

Бутырская Елена Васильевна - д.Х.н., проф. кафедры аналитической химии химического факультета, Воронежский государственный университет, Воронеж

Коломиец Людмила Николаевна - старший научный сотрудник, кандидат химических наук, Институт физической химии и электрохимии им. А.Н.Фрумкина РАН, Москва

Боровикова Светлана Александровна научный сотрудник, кандидат химических наук, Институт физической химии и электрохимии им. А.Н.Фрумкина РАН, Москва
Ganzhurova Maria A. - Master of the Department of Analytical Chemistry, Voronezh State University, Voronezh, E-mail: mikkimaus7@mail.ru

Myakisheva Marina S. - Master of the Department of Analytical Chemistry, Voronezh State University, Voronezh, E-mail: mjakishevams@yandex.ru

Butyrskaya Elena V. - Doctor of Chemical sciences, professor of Department of Analytical Chemistry of chemical faculty, Voronezh State University, Voronezh, E-mail: bev5105@yan$\underline{\text { dex.ru }}$

Kolomiets Liudmila N. - researcher, Ph.D. Frumkin Institute of Phisical and Electrochemistry, Moscow, e-mail: kolom_moscow@mail.ru

Borovikova Svetlana A. - researcher, Ph.D. Frumkin Institute of Phisical and Electrochemistry, Moscow 